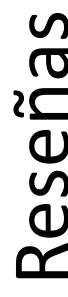

\title{
On China
}

Henry Kissinger

Nueva York, Penguin Press, 2011, 608 pp.

El primer aporte sustancial del ex Secretario de Estado Henry Kissinger en su meticuloso ensayo - ¿es un ensayo?- «On China» es que permite entender el devenir de China de las últimas décadas a la luz del prisma del pensamiento y la filosofía tradicional del «Imperio del Medio». Asimismo, la obra de Kissinger abre paso a comprender mejor el rol que juega y ha de jugar la República Popular China en la política mundial en los próximos tiempos. Se trata de un texto fundamental y una lección permanente sobre la filosofía y práctica de las negociaciones y el diálogo diplomático en general y con China en particular. Para los interesados en el tema de la evolución y emergencia de China en el escenario mundial experimentado en los últimos decenios, el texto resulta una obra indispensable: debe estudiarse y no simplemente leerse.

El primer acierto del autor es destacar sin error la singularidad de China en el ámbito internacional. Tal característica fue identificada por el propio Presidente Nixon cuando encargó a Henry Kissinger el restablecimiento de contactos con China, largamente abandonados en los años anteriores. Difícil habría sido para el entonces Presidente de los Estados Unidos encontrar un enviado mejor dotado para tan ardua como delicada e importante tarea. En efecto, el profundo conocimiento previo de China -de su historia pero también de su liderazgo y situación política- de Kissinger facilitó su tarea e hizo posible no solo abrir una nueva era en las relaciones de los Estados Unidos con China sino sentar las bases para una vinculación positiva y sustentable en la que la comprensión conceptual de 
lo que China entiende por orden internacional y lo que deben ser sus relaciones con el mundo exterior deberán para siempre ser tenidas en cuenta por la comunidad internacional. Tal es uno de los méritos principales de la obra «On China» del ex Secretario de Estado de los Estados Unidos.

La obra de Kissinger pone de manifiestodeja que el desconocimiento de la visión que la propia China tiene del mundo y su rol entre las naciones puede conducir a estadistas y diplomáticos -así como a hombres de negocios- a cometer errores difícilmente reversibles. Esa es una reflexión necesaria para quienes abordan la tarea de leer esta obra, si es que se interesan en interactuar con contrapartes de la República Popular China

La consistencia del conocimiento de China y su historia deben necesariamente estar presentes a la hora de diseñar políticas respecto de China por parte de Occidente. Tal es lo que insinúa insinua Kissinger. Con algunas diferencias, los países del entorno geográfico de China deben asumir la misma prudencia.

El ex Secretario de Estado compara con acierto el talante «misionero» de los Estados Unidos -y de Europa, por ciertocon la «singularidad» cultural de China. El autor propone que China no ha dejado enteramente de lado su condición de heredera del «Imperio del Medio», en virtud del cual China ha considerado históricamente a los demás países y reinos como entidades tributarias. Kissinger advierte señales que muestran que la tradición intelectual del «Imperio del Medio» no ha desaparecido del todo.

A partir de esas concepciones básicas, Kissinger nos proporciona un relato histórico profundamente informado, actual y de valor permanente, del diálogo diplomático desarrollado en décadas recientes entre Washington y Beijing, que en buena parte permite explicar el punto en que actualmente se encuentra Occidente, en lo que al rol de la República Popular China se refiere. Resulta fundamental, asimismo, el aporte de Henry Kissinger para aclarar el sentido de la evolución desde el maoismo duro al socialismo de mercado que evidencia actualmente China a ojos de muchos analistas.

Kissinger señala, a título de consejo, que cualquier intento de entender la actual diplomacia china o el rol de este país en el siglo XXI debe empezar por una apreciación básica del 
contexto en que China ha evolucionado desde sus inicios históricos, que se hunden en los siglos, y acerca de los cuales hay pocos antecedentes precisos. Anota el autor que China ha sido capaz de mantener una persistencia cultural a lo largo de su historia que la hace única entre las naciones, siendo este el concepto básico que debe tenerse presente en cualquier vinculación diplomática, académica o empresarial con la R.P. China. Con acierto señala Kissinger que «Tras un viaje incierto y en ocasiones accidentado, China llega por fin a la perspectiva deseada por reformistas y revolucionarios en los dos últimos siglos: un país próspero que muestra al mundo su capacidad militar al mismo tiempo que conserva sus valores distintivos»: China puede participar de igual a igual en la gestión de los asuntos internacionales junto a las demás grandes potencias, conservando su singularidad que la destaca entre las naciones. (La cita está tomada de la página 518 de la versión en castellano de Editorial Debate, Buenos Aires, 2012). Resultará útil recordar esta cita, si es que a la vez tenemos presente la frase de Hu Jintao pronunciada en 2005 en su conferencia titulada «Sentar la base para un mundo armonioso con una paz duradera y prosperidad para todos» durante la Asamblea General de Naciones Unidas»: «La nación china ama la paz. El desarrollo chino no va a perjudicar ni amenazar a nadie, antes bien servirá a la causa de la paz, de la estabilidad y de la prosperidad común en el mundo».

Para acallar debates y tranquilizar ánimos y suspicacias, en las páginas finales de esta excelente obra Kissinger cita las palabras de Dai Bingguo, Consejero de Estado de la R.P. China, quien en diciembre de 2010 definió la política global china en su artículo «Seguimos optando por el desarrollo pacífico» señalando que «La insistencia en adoptar la vía del desarrollo pacífico no es algo producto de una imaginación subjetiva o de algún cálculo concreto, sino más bien el resultado del reconocimiento de que tanto el mundo actual como la China de hoy en día han vivido unos cambios terribles y de que las relaciones de este país con el mundo también han experimentado cambios importantes; así pues, hace falta aprovechar la situación al máximo y adaptarse a las modificaciones». Útil cita por cierto, con la que Kissinger consigue acallar suspicacias.(pág 522 en la versión en la citada versión de Editorial Debate),. Se trata 
de una cita del propio Ministerio de Relaciones Exteriores de la R.P. China, el 6 de diciembre de 2010.

Más allá del irreemplazable testimonio de sus conversaciones con el liderazgo chino, que por sí solo constituye un documento histórico de primera importancia y sin el cual con certeza no habría otra constancia detallada de esos diálogos, la obra de Kissinger constituye un aporte insuperable para la reflexión académica, el trabajo diplomático y la decisión de los estadistas. La magnífica obra "On China» de Henry Kissinger deja fuera, sin embargo, el tema de la relación de China con otros actores principales -Europa Occidental, Australia- y con regiones emergentes, como América Latina y África. Tales comentarios, inspirados en el conocimiento profundo de la conducta internacional de China que exhibe Kissinger, haràn falta en la planificación diplomática futura de muchos países.

Se trata de una obra que no sóoo debe leerse sino que deberá considerarse un texto de estudio indispensable.

José Miguel de la Cruz Director Asia-Pacifico, Ministerio de Relaciones Exteriores, Chile 